\title{
Consultation on kidney stones, Copenhagen 2019: aspects of intracorporeal lithotripsy in flexible ureterorenoscopy
}

\author{
Søren Kissow Lildal ${ }^{1} \cdot$ Kim Hovgaard Andreassen ${ }^{2} \cdot$ Joyce Baard $^{3} \cdot$ Marianne Brehmer $^{4,5} \cdot$ Matthew Bultitude $^{6}$. \\ Ylva Eriksson ${ }^{4,5} \cdot$ Khurshid R. Ghani $^{7} \cdot$ Helene Jung ${ }^{8} \cdot$ Guido Kamphuis $^{3} \cdot$ Peter Kronenberg $^{9} \cdot$ Ben Turney $^{10}$. \\ Olivier Traxer ${ }^{11} \cdot$ Øyvind Ulvik ${ }^{12}$ • Palle Jörn Sloth Osther ${ }^{8}$ (I)
}

Received: 22 August 2020 / Accepted: 1 October 2020 / Published online: 16 October 2020

(C) The Author(s) 2020

\begin{abstract}
Purpose To summarize current knowledge on intracorporeal laser lithotripsy in flexible ureterorenoscopy (fURS), regarding basics of laser lithotripsy, technical aspects, stone clearance, lithotripsy strategies, laser technologies, endoscopes, and safety. Methods A scoping review approach was applied to search literature in PubMed, EMBASE, and Web of Science. Consensus was reached through discussions at the Consultation on Kidney Stones held in September 2019 in Copenhagen, Denmark. Results and conclusions Lasers are widely used for lithotripsy during fURS. The Holmium laser is still the predominant technology, and specific settings for dusting and fragmenting have evolved, which has expanded the role of fURS in stone management. Pulse modulation can increase stone ablation efficacy, possibly by minimizing stone retropulsion. Thulium fibre laser was recently introduced, and this technology may improve laser lithotripsy efficiency. Small fibres give better irrigation, accessibility, and efficiency. To achieve optimal results, laser settings should be adjusted for the individual stone. There is no consensus whether the fragmentation and basketing strategy is preferable to the dusting strategy for increasing stone-free rate. On the contrary, different stone scenarios call for different lithotripsy approaches. Furthermore, for large stone burdens, all laser settings and lithotripsy strategies must be applied to achieve optimal results. Technology for removing dust from the kidney should be in focus in future research and development. Safety concerns about fURS laser lithotripsy include high intrarenal pressures and temperatures, and measures to reduce both those aspects must be taken to avoid complications. Technology to control these parameters should be targeted in further studies.
\end{abstract}

Keywords Laser lithotripsy $\cdot$ Ureteroscopy $\cdot$ Kidney stones $\cdot$ Endoscopes $\cdot$ Safety $\cdot$ Technology

Palle Jörn Sloth Osther posther@health.sdu.dk

1 Department of Urology, Aarhus University Hospital, Aarhus, Denmark

2 Department of Urology, Herlev-Gentofte Hospital, University of Copenhagen, Copenhagen, Denmark

3 Department of Urology, Amsterdam UMC, University of Amsterdam, Amsterdam, The Netherlands

4 Department of Surgery and Urology, Danderyd University Hospital, Stockholm, Sweden

5 Department of Clinical Sciences, Karolinska Institutet, Stockholm, Sweden

6 Urology Centre and Stone Unit, Guy's and St. Thomas' NHS Foundation Trust, London, UK
7 Department of Urology, University of Michigan, Ann Arbor, MI, USA

8 Department of Urology, Urological Research Center, Lillebaelt Hospital, University of Southern Denmark, Vejle, Denmark

9 Department of Urology, Hospital CUF Descobertas, Lisbon, Portugal

10 Department of Urology, Churchill Hospital, Oxford University Hospitals NHS Trust, Oxford, UK

11 Department of Urology, Tenon Hospital, Paris, France

12 Department of Urology, Haukeland University Hospital, Bergen, Norway 


\section{Introduction}

Flexible ureterorenoscopy (fURS) has evolved as one of the major modalities for upper urinary tract stone management. This development is largely the result of continuing advancements in laser technology for intracorporeal lithotripsy, which is the focus of this review. Most daily clinical practices in the field of kidney stones, including lithotripsy techniques, are not supported by randomized trials and metaanalyses. This is not due to low research activity in this area, but rather to difficulties in designing meaningful trials that reflect daily clinical practice, because stone disease is so diverse. In this context, it is particularly important for practising experts to share their knowledge on clinical applications. The concept of the meeting "Consultation on Kidney Stones", on which this review is based, was to create a forum for transfer and development of clinical expertise.

\section{Methods}

To evaluate lithotripsy in fURS regarding the balance between existing evidence, expert opinions, and safety and efficacy of new technological improvements, key opinion leaders in the field were invited to assess and discuss existing evidence at the 2-day meeting entitled "Consultation on Kidney Stones: Aspects of Intracorporeal Lithotripsy" held in Copenhagen, Denmark, in September 2019. The participating experts were assigned different topics and prepared presentations according to scoping reviews using PubMed, EMBASE, and Web of Science to search the literature. The first day of the meeting was open only to the experts, who individually presented their topics, which were then discussed by the whole group. The presentations were subsequently adjusted if necessary. The second day was an open meeting at which all presentations were given to an international audience, and this was followed by free discussions.

\section{Basics of laser lithotripsy}

\section{Laser fibre size}

The deflection range of a flexible ureteroscope decreases with increased size of the laser fibre inserted [1-3]. The size of the fibre also has an inverse effect on irrigation $[1,2]$. An in vitro study of the ablation efficiency of laser fibres showed that large fibres $(550 \mu \mathrm{m})$ produced wider fissures than small fibres $(200 \mu \mathrm{m})$, but the fissures made by the small fibres were deeper [4]. Another investigation found that using a larger fibre created more retropulsion of the stone during lithotripsy [5]. Comparison of total fragmentation volume indicated little difference between fibres except at very low pulse energies $(0.2 \mathrm{~J})$, at which small fibres were more efficient [4]. These observations suggest that smaller fibres provide the following: better irrigation and thus improved visibility; better deflection and hence increased accessibility; and less retropulsion and thus higher ablation efficiency, and also an overall reduction in operating time $[2,6]$.

\section{Laser fibre tips}

Laser fibres can have a standard flat tip or a polished or ballshaped tip. The ball-tip fibre is designed to reduce damaging friction forces generated within the working channel of the ureteroscope. It has been shown that this type of fibre can be safely passed through a deflected ureteroscope without causing liner perforation. The same advantage can be achieved by cleaving a standard fibre in such a manner that the coating protects the scope from the laser core [7]. Flat-tip fibres require greater insertion force at all angles and therefore can cause the ureteroscope liner to leak if it is deflected $45^{\circ}$ or more [8].

An in vitro study comparing lithotripsy performance of different types of laser fibres found that the standard fibre functioned just as well as specially designed fibres [9]. Kronenberg et al. [10] noted that, compared to fibres stripped off the coating material, coated fibres achieved significantly higher ablation volumes, and there was no difference in performance between coated fibres cleaved with metal or ceramic scissors. However, Aldoukhi et al. [11] observed that single-use fibres and cleaved reusable fibres performed better than fibres with tips cut using Mayor scissors. The difference in efficiency between stripped and coated fibres may be due to the fibre itself being damaged during the stripping off the coating, leading to a dispersion of laser energy $[10,11]$. Another downside of such stripping is that a fibre devoid of its coloured coating is difficult to discern in front of the ureteroscope. The above-mentioned factors have not been scientifically evaluated in vivo, and individual surgeons may have different preferences.

\section{Laser settings}

Various laser systems have been developed that offer different laser settings, such as high frequency and long-pulse duration. The total power (W) used is equal to the pulse energy (J) multiplied by the pulse frequency $(\mathrm{Hz})$. In an in vitro study, a combination of low frequency and high pulse energy was more effective than the opposite combination with the same total power level, and pulse energy and ablation volume were linearly correlated with the width and depth of fissures observed in the stone material [4]. However, high pulse energy resulted in more stone retropulsion, 
larger stone fragments, and laser fibre burn-back, all leading to prolonged operating time $[4,12]$. Lowering the pulse energy and increasing the frequency give rise to less retropulsion and fibre burn-back, which results in dusting of the stone. Regarding the pulse length, preliminary data from an in vitro study showed that short pulse settings led to significantly higher ablation volumes than long-pulse settings [13], whereas long-pulse lithotripsy was associated with less fibre burn-back, smaller fragments, and more dust. Other investigations have been unable to demonstrate a significant relationship between pulse duration and stone ablation [14, 15].

The Moses technology introduces a pulse-shaped modulation that optimizes energy delivery through water to the target stone. The Moses platform has two settings: Moses contact (MC) mode, for operation at close range $(<2 \mathrm{~mm})$; Moses distance (MD) mode, for lithotripsy at a distance of $2 \mathrm{~mm}$. In a preclinical study, the Moses technology resulted in more efficient laser lithotripsy with significantly reduced stone retropulsion [16]. In an automated in vitro dusting model, compared to long-pulse lithotripsy, Moses holmium:yttrium-aluminum-garnet (Ho:YAG) (Ho:YAG) laser technology provided greater ablation of soft stones when in contact with the stone surface [17]. In an investigation using a three-dimensional positioning system, researchers examined the impact of laser fibre working distance on fragmentation when altering pulse width or modulation [18], which showed that holmium laser lithotripsy was significantly affected by the fibre tip to stone working distance, with the greatest ablation volume obtained with the fibre in contact with the stone.

Considering optimal settings for the lithotriptor, different stone compositions require different settings to achieve the desired effect, and the desired effect may vary in individual situations. The recommendation is to start with a test setting of low pulse energy and low frequency to initially determine how the stone reacts, and thereafter adjust settings accordingly to improve efficiency of the lithotripsy.

\section{Technical aspects of laser lithotripsy and stone clearance during fURS}

Various methods for laser lithotripsy have been described, and combining them can lead to more efficient ablation and clearance of stones with different characteristics [19]. The techniques described include dusting (dancing/painting), chipping, fragmentation, popcorning, dustmenting, and popdusting, and all these strategies can be combined in different ways to achieve the desired outcome. Dancing/painting is done by moving the laser fibre from side to side over the surface of the stone, using dusting settings. Chipping entails lasering off small pieces from the edges of the stone leaving small fragments for spontaneous passage, whereas fragmenting involves cutting a stone into larger fragments for subsequent basket removal. The fragmentation and basketing strategy use a setting of low frequency $(4-10 \mathrm{~Hz})$ and high pulse energy (0.6-2.0 J); dusting uses a setting of high frequency $(15-80 \mathrm{~Hz})$ and low pulse energy $(0.2-0.5 \mathrm{~J})$; popcorning stones requires settings of moderate-to-high frequencies $(10-20[40] \mathrm{Hz})$ and moderate pulse energy $(1-1.5 \mathrm{~J})[20-23]$.

Popcorning refers to a non-contact technique in which the laser energy whirls around fragments that come in contact with the laser and breaks them into smaller pieces. Chawla et al. [20] conducted an in vitro investigation of popcorning with different laser settings and observed that $1.5 \mathrm{~J}$ and $40 \mathrm{~Hz}$ produced the greatest mean decrease in stone burden per amount of time used; however, such a high-power level cannot be recommended in vivo. In that study, settings of $1.0 \mathrm{~J}$ and $20 \mathrm{~Hz}$ were most efficient with regard to mean stone weight loss per total amount of energy used. Emiliani et al. [24] suggested that a good compromise for popcorning would be using a long pulse of $1.5 \mathrm{~J}$ and $20 \mathrm{~Hz}$ with a $270 \mu \mathrm{m}$ laser fibre and taking as much time as possible (>4 min) to produce clinically insignificant fragments. In another in vitro model, Aldoukhi et al. found that the popcorn te

chnique was more effective when the laser fibre was positioned in contact with the stone as compared to at a distance of $2 \mathrm{~mm}$ from the stone, and when performed in a small (11 $\mathrm{mm}$ ) rather than a larger calyceal model [25]. These in vitro studies do not replicate the clinical environment, and, working in a limited space, surgeons should always aim to choose a safe power level based on the irrigation flow applied and other factors, including outflow (access sheath) and temperature of the irrigation fluid.

Humphreys et al. [26] conducted a non-randomized prospective clinical comparative trial considering dusting versus fragmenting, and they found no statistically significant difference in stone-free rate (SFR) and no difference in complication rates between the two patient groups. However, although stones were significantly larger in the dusting arm (96 vs $63 \mathrm{~mm}^{2}, p<0.001$ ) the mean operative time was significantly shorter in that group (36 vs $67 \mathrm{~min}, p<0.001$ ). This agrees with clinical data showing that, for large stones, it is easier to control the complete stone burden during dusting, whereas fragmenting may result in fragments moving into multiple different calyces in which they must be dealt with, potentially prolonging OR time and reducing SFR.

Ureteroscopic lasering of lower pole stones can be challenging. The anatomy of the lower pole must be considered, because a long infundibular length, a narrow infundibular width, and a steep infundibulo-pelvic angle may have a negative impact on stone clearance, especially if more than one of these aspects is unfavourable [27-30]. Using a basket/ grasper to move the stone to another location can be a viable 
alternative that can facilitate lithotripsy, reduce scope damage, and aid fragment passage [31, 32]. Schuster et al. [33] compared SFR in patients with lower pole stones treated in situ and subjects with relocation of the stone before lithotripsy. For stones $>1 \mathrm{~cm}$ in size, complete clearance was obtained in $100 \%$ of cases by relocation versus $29 \%$ of cases in situ ( $p=0.005)$; the difference between the two groups was not significant for stones of $<1 \mathrm{~cm}$. Placing the patient in Trendelenburg position during surgery can facilitate stone relocation to the upper pole from other sites by creating a dependent upper pole; two randomized trials have demonstrated that this method results in shorter OR time, better SFR, less flexible ureteroscope manipulation, and less stone migration into the lower pole $[34,35]$. If the stone cannot be relocated due to size or anatomy, or if lithotripsy in situ is preferred, a ball-tip laser fibre can be safely introduced through a deflected scope.

The 2020 EAU Urolithiasis Guidelines recommend that only baskets made of Nitinol be used for fURS. A range of different baskets are available, such as triangular baskets, 4-wire baskets, smaller baskets for narrow locations, and larger baskets for strength. Baskets can also vary regarding penetration force, radial dilation force, and opening dynamics, and add different degrees of resistance to scope deflection [36]. Bach et al. [37] tested various sizes of baskets in five different endoscopes and found that, in contrast to laser fibres, the size of the basket did not influence the deflection of the scope, which made relocation of a stone easier than in in situ lithotripsy. However, the size of the basket had an inverse effect on irrigation flow. Conversely, Patel et al. [36] showed some limitation of deflection, which was greater for a 2.2 Fr compared to a $1.5 \mathrm{Fr}$ basket. In practice, these differences will vary depending on the type of ureteroscope employed and how long it has been in use, and the specific basket that is chosen.

Methods for the evacuation of small residual fragments include the glue-clot technique and irrigation/suction systems. In the glue-clot technique, autologous venous blood is injected into a calyx, where it agglutinates with stone fragments to form a clot that can be extracted with a basket [38]. In a randomized pilot study of 47 patients, an automated irrigation/suction pump system was tested and found to reduce mean operating time by $35 \%(p=0.04)$ and to increase SFR from 69 to $92 \%$ ( $p=0.048)$ compared with the standard pressurized technique [39].

\section{Comparing clinical outcome of different laser lithotripsy strategies}

Comparing fragmenting and dusting with regard to clinical outcomes has proven difficult, because the objective metrics for such comparison vary. The studies performed have differed regarding rates of pre-stenting and staged procedures, and ways of reporting complication grades, emergency room visits, intensive care admission, hospitalization, and re-intervention. Reports concerning follow-up also differ with regard to definitions of stone free, imaging modalities, and timing of the follow-up and repeat intervention rate. Stone free has been defined as zero fragment, $<2 \mathrm{~mm}$, or $>4 \mathrm{~mm}$ residual fragment. Imaging modality for follow-up varies between computed tomography (CT), kidney-ureter-bladder radiograph (KUB), ultrasound (US), or fluoroscopy at operation, and a large proportion of patients apparently have no follow-up imaging at all [40]. An assessment of administrative data in the United States showed that 39\% of patients had no imaging at 12 months post-surgery[41].

A retrospective study demonstrated that fragments $>4 \mathrm{~mm}$ in size were associated with significantly higher rates of stone growth leading to complications and need for re-intervention, whereas fragments of $>2 \mathrm{~mm}$ were likely to grow, but were not associated with complications or re-intervention [42]. Another retrospective investigation reported that the cumulative repeat surgery rate at 5 years after fURS was proportional to the size of residual fragments on post-operative CT [43]: with no visible residual fragments, fragments $<4 \mathrm{~mm}$, or fragments $>4 \mathrm{~mm}$, the rates were $3.5 \%, 8.2 \%$, and $46.2 \%$, respectively. CT has been reported to have a sensitivity of 95-100\% for residual fragments [44].

Eleven studies comparing spontaneous passage and fragmentation with active retrieval [45] were identified, but most of them could not be compared with each other due to differences in imaging modalities and definitions of SFR. Only three comparative, non-randomized studies of the various disintegration strategies in the treatment of renal stones were pinpointed (Table 1) [26, 46, 47]. Two of those assessments used CT for follow-up, whereas the third used KUB and US. Only one of those three studies reported the power settings for dusting and fragmentation, respectively.

In a randomized, double-blinded clinical trial comparing regular and Moses modes of Ho:YAG laser lithotripsy, Ibrahim et al. showed that the Moses technology was associated with significantly lower fragmentation/pulverization (stone dusting) and procedural times, which the authors explained by less retropulsion of stones during Moses mode lithotripsy [48].

Conclusive evidence for comparing spontaneous passage and active retrieval strategies is limited, and it is difficult to compare existing studies, because they vary regarding disintegration strategy, SFR criteria, and time and modality of imaging at follow-up. Moreover, the investigations have not systematically reported stone density and composition and post-operative complications. 
Table 1 Comparative studies regarding SFR with spontaneous passage vs active retrieval during lithotripsy

\begin{tabular}{|c|c|c|c|c|c|c|}
\hline \multirow[t]{2}{*}{ Cohort } & \multicolumn{2}{|l|}{ Lee et al. 2016} & \multicolumn{2}{|c|}{ Humphreys et al. 2018} & \multicolumn{2}{|l|}{ El-Nahas et al. 2019} \\
\hline & Spontaneous & Retrieval & Spontaneous & Retrieval & Spontaneous & Retrieval \\
\hline Study design & Retrospective & Retrospective & Prospective & Prospective & Retrospective & Retrospective \\
\hline Study period & 2010-2015 & 2010-2015 & 2013-2016 & 2013-2016 & 2015-2017 & 2015-2017 \\
\hline Cases, $n$ & 76 & 172 & 68 & 82 & 51 & 56 \\
\hline Mean stone size (SD) & $11 \mathrm{~mm}( \pm 5.2)$ & $11 \mathrm{~mm}( \pm 4.8)$ & $11 \mathrm{~mm}( \pm 4.3)$ & $8.8 \mathrm{~mm}( \pm 3.5)$ & NS & NS \\
\hline Laser power (setting) & NS & NS & 30-100 W (NS) & 30-100 W (NS) & $20-60 \mathrm{~W}(0.3 \mathrm{~J} / 20 \mathrm{~Hz})$ & $20-60 \mathrm{~W}(1.0 \mathrm{~J} / 10 \mathrm{~Hz})$ \\
\hline OR time & $82 \mathrm{~min}$ & $83 \mathrm{~min}$ & $36 \mathrm{~min}$ & $67 \mathrm{~min}$ & $76 \mathrm{~min}$ & $91 \mathrm{~min}$ \\
\hline Stenting rate & $100 \%$ & $100 \%$ & $100 \%$ & $100 \%$ & $100 \%$ & $100 \%$ \\
\hline Complications & $11 \% *$ & $11 \% *$ & $13.2 \% *$ & $19.5 \% * *$ & $8 \% *$ & $9 \% * *$ \\
\hline Definition of SFR & $<3 \mathrm{~mm}$ & $<3 \mathrm{~mm}$ & No fragment & No fragment & No fragment and $<4 \mathrm{~mm}$ & No fragment and $<4 \mathrm{~mm}$ \\
\hline Imaging used & $\mathrm{CT}$ & $\mathrm{CT}$ & KUB, US & KUB, US & $\mathrm{CT}$ & $\mathrm{CT}$ \\
\hline Imaging timing & 4 weeks & 4 weeks & 4-6 weeks & 4-6 weeks & 2 months & 2 months \\
\hline Stone free rate & $87 \%$ & $89 \%$ & $58 \%$ & $74 \%$ & $59 \%$ and $86 \%$ & $79 \%$ and $89 \%$ \\
\hline
\end{tabular}

$S D$ standard deviation, $O R$ operating room, $S F R$ stone-free rate, $C T$ computed tomography, $K U B$ kidney-ureter-bladder radiograph, $U S$ ultrasound

\section{Endoscopes and laser lithotripsy}

Ureteroscopes vary with respect to location of working channel (Fig. 1), deflection ability and irrigation flow with laser fibre inserted, distance of laser tip from the tip of the endoscope, and optical imaging quality and illumination of the surgical field. All of the listed features have a potential impact on laser lithotripsy, although evidence for this is based mainly on in vitro studies and expert opinions, and very little has been published regarding effects on clinical outcome.

The position of the working channel of the endoscope can influence irrigation flow and thus create differences in the flushing and movement of stone and tissue. The position also dictates location of the laser fibre/basket inserted through the channel and thereby affects the ability to reach stones in certain positions within the kidney [49].

In vitro comparison of single-use and reusable flexible ureteroscopes showed that the latter had bettervision characteristics [50]. It appears that scopes differ regarding occurrence of light flashes during laser lithotripsy, over-illumination of the field, and the speed at which light intensity can be regulated. These phenomena may occur due to automatic light intensity regulation being affected by laser energy flashes or by stone fragments or dust that is flushed around by irrigation and laser pulse pressure waves. The cited in vitro comparison also demonstrated that the flow varied between different flexible ureteroscopes equipped with the same type of laser fibre [50]. The problem of working channel damage can be almost completely overcome by employing single-use flexible ureteroscopes.
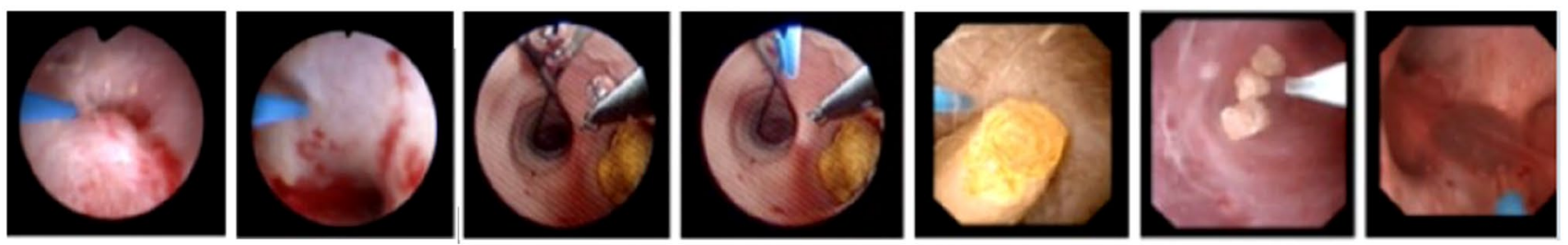

\begin{tabular}{|c|c|c|c|c|c|c|}
\hline Olympus URF-P5 & Karl Storz FlexX2 & Wolf Viper & Wolf Cobra & Olympus URF-V & Karl Storz FlexXC & ACMI DUR-D \\
\hline 9 o'clock & 9 o'clock $^{\prime}$ & 2 o'clock & $12+2$ o'clock & 9 o'clock & 3 o'clock & 6 o'clock \\
\hline
\end{tabular}

Fig. 1 Different positions of working channel depending on manufacturer and model of ureteroscope 


\section{Safety aspects of laser lithotripsy during fURS}

Direct contact of the laser can cause local burns on the urothelium. Furthermore, high-flow irrigation for optimal visualization and cooling leads to increased intraluminal pressure, although such irrigation is necessary.

It should also be noted that incorrect handling of lasers may damage the ureteroscope and even harm the surgeon and OR personnel. A safety distance between the tip of the fibre and the tip of the scope should be maintained to minimize the risk of damaging endoscopes. Talso et al. [51] observed that the length of the fibre projecting from ureteroscopes was 1-2 mm at first appearance in the camera image, whereas it was 3-4 $\mathrm{mm}$ when reaching onefourth of the screen, and in that position, the laser bubble was never in contact with the tip of the ureteroscope and was therefore protected from damage.

The incidence of ureteral perforation during ureterorenoscopy has been reported to be $0.4-6.3 \%$, and the risk factors identified included size of ureteroscope, prolonged operation time, surgeon's lack of experience, stone characteristics, lack of pre-stenting, and high laser energy $[52,53]$. Possible complications of perforation are extravasation, haematoma, sepsis, pain, obstruction, stricture, and loss of kidney function [52-55]. Use of laser during intracorporeal lithotripsy has been observed to be an independent risk factor, with a $3.6 \%$ risk of Post-ureteroscopic Lesion Scale (PULS; [56] grade 1 lesions and 3.1\% risk of PULS grade 2 lesions. To avoid ureteral perforation, it is recommended that optimal visualization be secured by irrigation and that a safety distance of at least $1 \mathrm{~mm}$ be maintained between laser tip and urothelium.

During laser lithotripsy, visualization can be impaired by stone dust and debris. Increasing irrigation to solve this problem unequivocally raises the intrarenal pressure, potentially leading to tubular, venous, and lymphatic backflow. Baseline intrarenal pressure is approximately $10 \mathrm{mmHg}$, and the threshold for backflow is $30-35 \mathrm{mmHg}$. Intrarenal pressure levels during fURS and holmium laser usage have been noted to be as high as $50-350 \mathrm{mmHg}$ $[57,58]$. Intrarenal pressures above $30 \mathrm{mmHg}$ for more than 10 min have been shown to significantly increase the incidence of septicaemia in percutaneous nephrolithotomy [59]. Although several studies have suggested that complications such as sepsis and post-operative pain leading to longer hospitalization are related to high intrarenal pressure, no definitive causal data exist [60-63]. Intrarenal pressure during fURS may be reduced by the use of a ureteral access sheath (UAS) [64]. If a UAS is to be applied, it must have a larger diameter than the scope, which make the UAS a double-edged sword: on one hand, it reduces intrarenal pressure and potential septic complications, and on the other hand, it may increase the risk of strain-induced lesions to the ureter [65]. Therefore, it is important to use the smallest UAS compatible with the ureteroscope chosen to ensure both safe placement without significant friction and sufficient outflow, and thereby achieve both low intrarenal pressure and sufficient flow for visualization during lithotripsy [66].

High intrarenal temperatures have been observed during laser lithotripsy, especially at high total power settings ( $>30 \mathrm{~W}$ ) [67]. High temperatures can lead to thermal ablation of kidney tissue, resulting in permanent kidney damage. Overall, such tissue damage is dependent on temperature, time, and blood flow [68]. In the ureter, the threshold for tissue damage has been shown to be around $43{ }^{\circ} \mathrm{C}$ for $120 \mathrm{~min}$, which is equivalent to approximately $50{ }^{\circ} \mathrm{C}$ for $56 \mathrm{~s}$ or $56^{\circ} \mathrm{C}$ for $0.9 \mathrm{~s}$ [69-71]. In an in vitro model, Wollin et al. achieved temperatures of $>43{ }^{\circ} \mathrm{C}$ at all laser settings within 1 min without irrigation, and the maximum temperature reached was $100{ }^{\circ} \mathrm{C}$ at fragmentation settings [69]. Aldoukhi et al. recorded temperatures in a pig kidney during high-power holmium laser lithotripsy at $0.5 \mathrm{~J}$ and $80 \mathrm{~Hz}$ and different irrigation flows, and found that only high irrigation flow (38-40 $\mathrm{ml} / \mathrm{min}$ ) could keep the caliceal temperature at $\leq 43{ }^{\circ} \mathrm{C}$ [72]. To reduce heating, it is important to have secured continuous flow irrigation and consider use of room temperature or even cooled irrigation fluid. Lasering should be carried out intermittently to allow cooling in low-flow areas.

\section{Comparison of different laser technologies for intracorporeal lithotripsy}

The past and current standard for laser lithotripsy is the Ho:YAG laser, which has revolutionized retrograde stone management. Introduction of high-power Ho:YAG laser systems that utilize laser settings of high frequency and low pulse energy (HiFr-LoPE), varying pulse lengths, and Moses technology for reduction of retropulsion and improvement of fragmentation have expanded the surgeon's ability to ablate urinary tract stones and thereby opened a new era for the dusting technique. Reducing the need for fragment retrieval and the potential hazards of this technique (UAS usage and multiple scope passages) may be advantageous [73]. Recently, a new laser technology for stone management has emerged - the thulium fibre laser (TFL). The TFL emits light with a wavelength of $1940 \mathrm{~nm}$, compared to $2100 \mathrm{~nm}$ with Ho:YAG [74-79]. Comparing laser setting options, TFL offers frequencies of $5-2200 \mathrm{~Hz}$, pulse energies of $0.025-6 \mathrm{~J}$, and pulse durations of 200-12,000 microsec [76, 80-83], whereas Ho:YAG offers 5-100 Hz, 0.2-6 J, and 50-1300 microsec $[81,84]$. These qualities of the TFL laser 
give this technology the potential to produce 3-4 times more dust compared to high-power Ho-YAG lasers [78, 85, 86]. Furthermore, due to the novel laser beam generation by laser diodes in TFL, smaller fibres $(50 \mu \mathrm{m})$ can be utilized, which may result in higher energy intensity at the tip of the fibre, better scope deflection, and better irrigation, all of which can potentially increase stone ablation volume at comparable settings [74, 80, 81]. Initial reports of TFL performance in the clinical setting are promising but still limited [87], and further evaluation, including consideration of safety aspects (temperature) and ability of the laser to embrace all lithotripsy strategies, will be necessary to define the role of TFL. To date, no clinical comparative studies of holmium and thulium fibre lasers have been conducted. Nevertheless, both the HiFr-LoPE Ho:YAG and the new TFL technology show promise in expanding the role of flexible ureteroscopic stone management by approaching larger stones and more complex stone scenarios.

\section{Conclusions}

Lasers have revolutionized the scenario of intracorporeal lithotripsy during fURS. Ho:YAG is still the predominant laser for stone management, and, with this technology, specific settings for dusting and fragmenting have evolved, which have expanded the role of fURS in endoscopic stone management. Recently, the TFL was introduced, and this new laser source may prove to further increase the efficiency of laser lithotripsy. There is still debate as to whether the fragmentation and basketing strategy are preferable to the dusting strategy for increasing SFR. However, one does not exclude the other, because different stone scenarios call for different lithotripsy approaches, and, for large stone burdens, all laser lithotripsy settings (dusting, fragmenting, and popcorning) may often be necessary for optimizing the final result. Technology for removing dust from the kidney should be a focus for future research and development. Safety aspects of fURS laser lithotripsy include high intrarenal pressures and temperatures. Inasmuch as measures to reduce both pressure and temperature are mandatory to avoid sepsis, bleeding, and nephron loss, technology to control these parameters should be targeted in further investigations.

Acknowledgements We are grateful to Boston Scientific, Olympus, Coloplast, Cook Medical, EMS, Lumenis, Richard Wolf, Karl Storz Endoscope, Apsu Medical, BL Medical, Opiva Nordic, and Rocamed for supporting the Copenhagen Consultation on Kidney Stones meeting 2019. We thank chief assistant Katrine Lindholtz for outstanding administrative management, Stockholm Data Design AB for managing the website, and Patricia Ödman for language revision.

Author contributions SKL: data analysis and manuscript writing. KA: data analysis and manuscript editing. JB: data analysis and manuscript editing. MBr: project co-ordination, presentation, manuscript editing.
$\mathrm{MBu}$ : data collection and analysis, presentation, and manuscript editing. YE: data analysis and manuscript editing. KG: data collection and analysis, presentation, and manuscript editing. HJ: data collection and analysis, presentation, and manuscript editing. GK: data collection and analysis, presentation, and manuscript editing. PK: data collection and analysis, presentation, and manuscript editing. BT: data analysis and manuscript editing. OT: data collection and analysis, presentation, and manuscript editing. ØU: data analysis and manuscript editing. PO: project co-ordination, data analysis, presentation, manuscript writing, and editing.

\section{Compliance with ethical standards}

Conflict of interest Søren K. Lildal: no conflicts of interest. Kim Andreassen: consultant for AMBU. Joyce Baard: no conflicts of interest. Marianne Brehmer: no conflicts of interest. Matthew Bultitude: consultant for Boston Scientific. Ylva Eriksson: no conflicts of interest. Khurshid Ghani: consultant for Boston Scientific, Lumenis, and Olympus; Grant from Boston Scientific. Helene Jung: no conflicts of interest. Guido Kamphuis: consultant for Boston Scientific and Olympus. Peter Kronenberg: consultant for Olympus. Ben Turney: no conflicts of interest. Olivier Traxer: consultant for Boston Scientific, Olympus, Rocamed, and Coloplast. Øyvind Ulvik: consultant for Olympus. Palle J S Osther: consultant for Olympus, Boston Scientific, Bonvisi AB, and Coloplast.

Informed consent Informed consent is not relevant.

Human and animal rights This is a review article involving no studies of human participants and/or animals.

Open Access This article is licensed under a Creative Commons Attribution 4.0 International License, which permits use, sharing, adaptation, distribution and reproduction in any medium or format, as long as you give appropriate credit to the original author(s) and the source, provide a link to the Creative Commons licence, and indicate if changes were made. The images or other third party material in this article are included in the article's Creative Commons licence, unless indicated otherwise in a credit line to the material. If material is not included in the article's Creative Commons licence and your intended use is not permitted by statutory regulation or exceeds the permitted use, you will need to obtain permission directly from the copyright holder. To view a copy of this licence, visit http://creativecommons.org/licenses/by/4.0/.

\section{References}

1. Kronenberg P, Traxer O (2015a) Update on lasers in urology 2014: current assessment on holmium:yttrium-aluminum-garnet (Ho:YAG) laser lithotripter settings and laser fibers. World J Urol 33(4):463-469

2. Kronenberg P, Traxer O (2014a) The truth about laser fiber diameters. Urology 84(6):1301-1307

3. Pasqui F, Dubosq F, Tchala K, Tligui M, Gattegno B, Thibault $P$ et al (2004) Impact on active scope deflection and irrigation flow of all endoscopic working tools during flexible ureteroscopy. Eur Urol 45(1):58-64

4. Kronenberg P, Traxer O (2014b) In vitro fragmentation efficiency of holmium: yttrium-aluminum-garnet (YAG) laser lithotripsy-a comprehensive study encompassing different frequencies, pulse energies, total power levels and laser fibre diameters. BJU Int 114(2):261-267 
5. Kronenberg P, Traxer O (2013) V1718 laser fibers, pulse energy and retropulsion-what we can see and what we can't. J Urol 189(4s):e707

6. Kronenberg P, Somani B (2018) Advances in lasers for the treatment of stones-a systematic review. Curr Urol Rep 19(6):45

7. Baghdadi M, Emiliani E, Talso M, Servián P, Barreiro A, Orosa A et al (2017) Comparison of laser fiber passage in ureteroscopic maximum deflection and their influence on deflection and irrigation: Do we really need the ball tip concept? World J Urol 35(2):313-318

8. Carlos EC, Li J, Young BJ, Radvak D, Wollin DA, Winship BB et al (2019) Let's get to the point: comparing insertion characteristics and scope damage of flat-tip and ball-tip holmium laser fibers. J Endourol 33(1):22-26

9. Kronenberg P, Traxer O (2016a) Lithotripsy performance of specially designed laser fiber tips. J Urol 195(5):1606-1612

10. Kronenberg P, Traxer O (2015b) Are we all doing it wrong? Influence of stripping and cleaving methods of laser fibers on laser lithotripsy performance. J Urol 193(3):1030-1035

11. Aldoukhi AH, Knudsen BE, Black KM, Hall TL, Roberts WW, Ghani KR (2019) Are we cutting ourselves short? Laser lithotripsy performance based on differences in fiber-tip preparation. Urology 134(1):79-83

12. Sea J, Jonat LM, Chew BH, Qiu J, Wang B, Hoopman J et al (2012) Optimal power settings for holmium:YAG lithotripsy. J Urol 187(3):914-919

13. Kronenberg P, Traxer O (2016b) Ultra-short, short, medium and long-pulse laser lithotripsy performance. Eur Urol Suppl 15(3):e1035

14. Sroka R, Pongratz T, Scheib G, Khoder W, Stief CG, Herrmann $T$ et al (2015) Impact of pulse duration on Ho:YAG laser lithotripsy: treatment aspects on the single-pulse level. World J Urol 33(4):479-485

15. Bader MJ, Pongratz T, Khoder W, Stief CG, Herrmann T, Nagele $\mathrm{U}$ et al (2015) Impact of pulse duration on Ho:YAG laser lithotripsy: fragmentation and dusting performance. World J Urol 33(4):471-477

16. Elhilali MM, Badaan S, Ibrahim A, Andonian S (2017) Use of the Moses technology to improve holmium laser lithotripsy outcomes: a preclinical study. J Endourol 31(6):598-604

17. Winship B, Wollin D, Carlos E, Li J, Peters C, Simmons WN et al (2018) Dusting efficiency of the Moses holmium laser: an automated in vitro assessment. J Endourol 32(12):1131-1135

18. Aldoukhi AH, Roberts WW, Hall TL, Ghani KR (2019) Watch your distance: the role of laser fiber working distance on fragmentation when altering pulse width or modulation. J Endourol 33(2):120-126

19. Hecht SL, Wolf JSJ (2013) Techniques for holmium laser lithotripsy of intrarenal calculi. Urology 81(2):442-445

20. Chawla SN, Chang MF, Chang A, Lenoir J, Bagley DH (2008) Effectiveness of high-frequency holmium:YAG laser stone fragmentation: the "popcorn effect." J Endourol 22(4):645-650

21. Weiss B, Shah O (2016) Evaluation of dusting versus basketing-can new technologies improve stone-free rates? Nat Rev Urol 13(12):726-733

22. Doizi S, Keller EX, De Coninck V, Traxer O (2018) Dusting technique for lithotripsy: what does it mean? Nat Rev Urol 15(11):653-654

23. Aldoukhi AH, Roberts WW, Hall TL, Ghani KR (2017) Holmium laser lithotripsy in the new stone age: dust or bust? Front Surg $4: 1-6$

24. Emiliani E, Talso M, Cho S-Y, Baghdadi M, Mahmoud S, Pinheiro $\mathrm{H}$ et al (2017) Optimal settings for the noncontact holmium:YAG stone fragmentation popcorn technique. J Urol 198(3):702-706
25. Aldoukhi AH, Roberts WW, Hall TL, Teichman JMH, Ghani KR (2018) Understanding the popcorn effect during holmium laser lithotripsy for dusting. Urology 122:52-57

26. Humphreys MR, Shah OD, Monga M, Chang Y-H, Krambeck AE, Sur RL et al (2018) Dusting versus basketing during ureteroscopy-which technique is more efficacious? A prospective multicenter trial from the EDGE research consortium. J Urol 199(5):1272-1276

27. Elbahnasy AM, Shalhav AL, Hoenig DM, Elashry OM, Smith DS, McDougall EM et al (1998) Lower caliceal stone clearance after shock wave lithotripsy or ureteroscopy: the impact of lower pole radiographic anatomy. J Urol 159(3):676-682

28. Inoue $\mathrm{T}$, Murota $\mathrm{T}$, Okada $\mathrm{S}$, Hamamoto $\mathrm{S}$, Muguruma K, Kinoshita $\mathrm{H}$ et al (2015) Influence of pelvicaliceal anatomy on stone clearance after flexible ureteroscopy and holmium laser lithotripsy for large renal stones. J Endourol 29(9):998-1005

29. Jessen JP, Honeck P, Knoll T, Wendt-Nordahl G (2014) Flexible ureterorenoscopy for lower pole stones: influence of the collecting system's anatomy. J Endourol 28(2):146-151

30. Danilovic A, Rocha BA, Torricelli FCM, Marchini GS, Batagello C, Vicentini FC et al (2019) Size is not everything that matters: preoperative CT predictors of stone free after RIRS. Urology 132:63-68

31. Kourambas J, Delvecchio FC, Munver R, Preminger GM (2000) Nitinol stone retrieval-assisted ureteroscopic management of lower pole renal calculi. Urology 56(6):935-939

32. Auge BK, Dahm P, Wu NZ, Preminger GM (2001) Ureteroscopic management of lower-pole renal calculi: technique of calculus displacement. J Endourol 15(8):835-838

33. Schuster TG, Hollenbeck BK, Faerber GJ, Wolf JSJ (2002) Ureteroscopic treatment of lower pole calculi: comparison of lithotripsy in situ and after displacement. J Urol 168(1):43-45

34. Pan J, Xue W, Xia L, Zhong H, Zhu Y, Du Z et al (2014) Ureteroscopic lithotripsy in Trendelenburg position for proximal ureteral calculi: a prospective, randomized, comparative study. Int Urol Nephrol 46(10):1895-1901

35. Zhou R, Han C, Hao L, Chen B, Zang G, Fan T et al (2018) Ureteroscopic lithotripsy in the Trendelenburg position for extracting obstructive upper ureteral obstruction stones: a prospective, randomized, comparative trial. Scand J Urol 52(4):291-295

36. Patel N, Akhavein A, Hinck B, Jain R, Monga M (2017) Tipless nitinol stone baskets: comparison of penetration force, radial dilation force, opening dynamics, and deflection. Urology 103:256-260

37. Bach T, Geavlete B, Herrmann TRW, Gross AJ (2008) Working tools in flexible ureterorenoscopy-influence on flow and deflection: what does matter? J Endourol 22(8):1639-1643

38. Cloutier J, Cordeiro ER, Kamphuis GM, Villa L, Letendre J, de la Rosette JJ et al (2014) The glue-clot technique: a new technique description for small calyceal stone fragments removal. Urolithiasis 42(5):441-444

39. Lechevallier E, Luciani M, Nahon O, Lay F, Coulange C (2003) Transurethral ureterorenolithotripsy using new automated irrigation/suction system controlling pressure and flow compared with standard irrigation: a randomized pilot study. J Endourol 17(2):97-101

40. Ghani KR, Wolf JSJ (2015) What is the stone-free rate following flexible ureteroscopy for kidney stones? Nat Rev Urol 12(5):281-288

41. Ahn JS, Holt SK, May PC, Harper JD (2018) National imaging trends after ureteroscopic or shock wave lithotripsy for nephrolithiasis. J Urol 199(2):500-507

42. Chew BH, Brotherhood HL, Sur RL, Wang AQ, Knudsen BE, Yong C et al (2016) Natural history, complications and re-intervention rates of asymptomatic residual stone fragments after 
ureteroscopy: a report from the EDGE research consortium. J Urol 195(4 Pt 1):982-986

43. Portis AJ, Laliberte MA, Heinisch A (2015) Repeat surgery after ureteroscopic laser lithotripsy with attempted complete extraction of fragments: long-term follow-up. Urology 85(6):1272-1278

44. Bhojani N, Paonessa JE, El Tayeb MM, Williams JCJ, Hameed TA, Lingeman JE (2018) Sensitivity of noncontrast computed tomography for small renal calculi with endoscopy as the gold standard. Urology 117:36-40

45. Fayad AS, Elsheikh MG, Ghoneima W (2017) Tubeless minipercutaneous nephrolithotomy versus retrograde intrarenal surgery for lower calyceal stones of $2 \mathrm{~cm}$ : a prospective randomised controlled study. Arab J Urol 15(1):36-41

46. Lee YJ, Bak DJ, Chung J-W, Lee JN, Kim HT, Yoo ES et al (2016) Is it necessary to actively remove stone fragments during retrograde intrarenal surgery? Investig Clin Urol 57(4):274-279

47. El-Nahas AR, Almousawi S, Alqattan Y, Alqadri IM, Al-Shaiji TF, Al-Terki A (2019) Dusting versus fragmentation for renal stones during flexible ureteroscopy. Arab J Urol 17(2):138-142

48. Ibrahim A, Elhilali MM, Fahmy N, Carrier S, Andonian S (2020) Double-blinded prospective randomized clinical trial comparing regular and moses modes of holmium laser lithotripsy. J Endourol 34(5):624-628

49. Villa L, Ventimiglia E, Proietti S, Giusti G, Briganti A, Salonia A et al (2020) Does working channel position influence the effectiveness of flexible ureteroscopy? Results from an in vitro study. BJU Int 125(3):449-456

50. Dragos LB, Somani BK, Keller EX, de Coninck VMJ, Herrero MR-M, Kamphuis GM et al (2019) Characteristics of current digital single-use flexible ureteroscopes versus their reusable counterparts: an in-vitro comparative analysis. Transl Androl Urol 8(Suppl 4):S359-S370

51. Talso M, Emiliani E, Haddad M, Berthe L, Baghdadi M, Montanari $\mathrm{E}$ et al (2016) Laser fiber and flexible ureterorenoscopy: the safety distance concept. J Endourol 30(12):1269-1274

52. De Cruz JE, Morcillo E, Folkersma LR, Alvarez S, Margallo FMS, Soria F (2017) Complications of endourologic procedures: a review on iatrogenic ureteral perforation. ARC J Urol 2(2):17-24

53. Cornu JN, Herrmann T, Traxer O, Matlaga B (2016) Prevention and management following complications from endourology procedures. Eur Urol Focus 2(1):49-59

54. Paiva MM, da Silva RD, Jaworski P, Kim FJ, Molina WR (2016) Subcapsular hematoma after ureteroscopy and laser lithotripsy. Can J Urol 23(4):8385-8387

55. Srougi V, Padovani GP, Marchini GS, Vicentini FC, Mazzucchi E, Srougi M (2015) Outcomes of surgical treatment of ureteral strictures after laser ureterolithotripsy for impacted stones. Can J Urol 22(6):8079-8084

56. Schoenthaler M, Buchholz N, Farin E, Ather H, Bach C, Bach $T$ et al (2014) The Post-Ureteroscopic Lesion Scale (PULS): a multicenter video-based evaluation of inter-rater reliability. World J Urol 32(4): 1033-1040

57. Jung H, Osther PJS (2015) Intraluminal pressure profiles during flexible ureterorenoscopy. Springerplus 4:373

58. Wilson W, Preminger G (1990) Intrarenal pressures generated during flexible deflectable ureterorenoscopy. J Endourol $4(2): 135-141$

59. Guo H-Q, Shi H-L, Li X-G, Gan W-D, Zeng L-Q, Liu G-X et al (2008) Relationship between the intrapelvic perfusion pressure in minimally invasive percutaneous nephrolithotomy and postoperative recovery. Zhonghua Wai Ke Za Zhi 46(1):52-54

60. Alsyouf M, Abourbih S, West B, Hodgson H, Baldwin DD (2018) Elevated renal pelvic pressures during percutaneous nephrolithotomy risk higher postoperative pain and longer hospital stay. J Urol 199(1):193-199

61. Whitehurst LA, Somani BK (2017) Perirenal hematoma after ureteroscopy: a systematic review. J Endourol 31(5):438-445

62. Uchida Y, Takazawa R, Kitayama S, Tsujii T (2018) Predictive risk factors for systemic inflammatory response syndrome following ureteroscopic laser lithotripsy. Urolithiasis 46(4):375-381

63. Fan S, Gong B, Hao Z, Zhang L, Zhou J, Zhang Y et al (2015) Risk factors of infectious complications following flexible ureteroscope with a holmium laser: a retrospective study. Int J Clin Exp Med 8(7):11252-11259

64. Ng YH, Somani BK, Dennison A, Kata SG, Nabi G, Brown $S$ (2010) Irrigant flow and intrarenal pressure during flexible ureteroscopy: the effect of different access sheaths, working channel instruments, and hydrostatic pressure. J Endourol 24(12):1915-1920

65. Osther PJS (2018) Risks of flexible ureterorenoscopy: pathophysiology and prevention. Urolithiasis 46(1):59-67

66. Al-Qahtani SM, Letendre J, Thomas A, Natalin R, Saussez T, Traxer O (2014) Which ureteral access sheath is compatible with your flexible ureteroscope? J Endourol 28(3):286-290

67. Hein S, Petzold R, Suarez-Ibarrola R, Müller P-F, Schoenthaler M, Miernik A (2020) Thermal effects of Ho:YAG laser lithotripsy during retrograde intrarenal surgery and percutaneous nephrolithotomy in an ex vivo porcine kidney model. World J Urol 38(3):753-760

68. Brehmer M, Svensson I (2000) Heat-induced apoptosis in human prostatic stromal cells. BJU Int 85(4):535-541

69. Wollin DA, Carlos EC, Tom WR, Simmons WN, Preminger GM, Lipkin ME (2018) Effect of laser settings and irrigation rates on ureteral temperature during holmium laser lithotripsy, an in vitro model. J Endourol 32(1):59-63

70. Aldoukhi AH, Ghani KR, Hall TL, Roberts WW (2017) Thermal response to high-power holmium laser lithotripsy. J Endourol 31(12):1308-1312

71. Sapareto SA, Dewey WC (1984) Thermal dose determination in cancer therapy. Int J Radiat Oncol Biol Phys 10(6):787-800

72. Aldoukhi AH, Hall TL, Ghani KR, Maxwell AD, MacConaghy B, Roberts WW (2018) Caliceal fluid temperature during high-power holmium laser lithotripsy in an in vivo porcine model. J Endourol 32(8):724-729

73. Tracey J, Gagin G, Morhardt D, Hollingsworth J, Ghani KR (2018) Ureteroscopic high-frequency dusting utilizing a 120-W holmium laser. J Endourol 32(4):290-295

74. Blackmon RL, Irby PB, Fried NM (2010) Thulium fiber laser lithotripsy using tapered fibers. Lasers Surg Med 42(1):45-50

75. Blackmon RL, Irby PB, Fried NM (2011) Comparison of holmium:YAG and thulium fiber laser lithotripsy: ablation thresholds, ablation rates, and retropulsion effects. J Biomed Opt 16(7):071403

76. Hardy LA, Gonzalez DA, Irby PB, Fried NM (2018) Fragmentation and dusting of large kidney stones using compact, air-cooled, high peak power, 1940-nm, thulium fiber laser. In: Kang HW, Chan KF (eds) Therapeutics and diagnostics in urology 2018. SPIE; 2018, pp 57-61

77. Ventimiglia E, Doizi S, Kovalenko A, Andreeva V, Traxer O (2020) Effect of temporal pulse shape on urinary stone phantom retropulsion rate and ablation efficiency using holmium:YAG and super-pulse thulium fibre lasers. BJU Int 126(1):159-167. https:// doi.org/10.1111/bju.15079

78. Andreeva V, Vinarov A, Yaroslavsky I, Kovalenko A, Vybornov A, Rapoport L et al (2020) Preclinical comparison of superpulse thulium fiber laser and a holmium:YAG laser for lithotripsy. World J Urol 38(2):497-503 
79. White MD, Moran ME, Calvano CJ, Borhan-Manesh A, Mehlhaff BA (1998) Evaluation of retropulsion caused by holmium:YAG laser with various power settings and fibers. J Endourol 12(2):183-186

80. Fried NM (2018) Recent advances in infrared laser lithotripsy [Invited]. Biomed Opt Express 9(9):4552-4568

81. Traxer O, Keller EX (2019) Thulium fiber laser: the new player for kidney stone treatment? A comparison with holmium:YAG laser. World J Urol. https://doi.org/10.1007/s00345-019-02654-5

82. Ergakov D, Martov AG, Guseynov M (2018) The comparative clinical study of Ho: YAG and SuperPulse Tm fiber laser lithotripters. Eur Urol Suppl 17(2):e1391

83. Yaroslavsky I, Vinnichenko V, McNeill T, Novoseltseva A, Perchuk I, Vybornov A et al (2018) Optimization of a novel Tm fiber laser lithotripter in terms of stone ablation efficiency and retropulsion reduction. In: procspie. 2018, p 104680H (Society of Photo-Optical Instrumentation Engineers (SPIE) Conference Series; vol. 10468)

84. Fried NM, Irby PB (2018) Advances in laser technology and fibreoptic delivery systems in lithotripsy. Nat Rev Urol 15(9):563-573
85. Traxer O, Rapoport L, Tsarichenko D, Dymov A, Enikeev D, Sorokin N et al (2018) V03-02 first clinical study on superpulse thulium fiber laser for lithotripsy. J Urol 199(4S):e321-e322

86. De Coninck VMJ, Keller EX, Kovalenko A, Vinnichenko V, Traxer O (2019) Dusting efficiency comparison between Moses technology of Ho:YAG laser and superpulse thulium fiber laser. Eur Urol Suppl 18(1):e1757-e1758

87. Enikeev D, Taratkin M, Klimov R, Alyaev Y, Rapoport L, Gazimiev M et al (2020) Thulium-fiber laser for lithotripsy: first clinical experience in percutaneous nephrolithotomy. World J Urol. https://doi.org/10.1007/s00345-020-03134-x

Publisher's Note Springer Nature remains neutral with regard to jurisdictional claims in published maps and institutional affiliations. 